\title{
Optimization of heat- and ultrasound-assisted extraction of anthocyanins from Hibiscus sabdariffa calyces for natural food colorants
}

\author{
José Pinela $^{\mathrm{a}}$, M.A. Prieto ${ }^{\mathrm{a}, \mathrm{b}}$, Eliana Pereira ${ }^{\mathrm{a}}$, Inès Jabeur ${ }^{\mathrm{a}}$, Maria Filomena Barreiro ${ }^{\mathrm{a}, \mathrm{c}}$, \\ Lillian Barros ${ }^{\mathrm{a}}$, Isabel C.F.R. Ferreira ${ }^{\mathrm{a}, *}$ \\ a Centro de Investigação de Montanha (CIMO), Instituto Politécnico de Bragança, Campus de Santa Apolónia, 5300-253 Bragança, Portugal \\ ${ }^{\mathrm{b}}$ Nutrition and Bromatology Group, Faculty of Food Science and Technology, University of Vigo, Ourense Campus, E32004 Ourense, Spain \\ ${ }^{\mathrm{c}}$ Laboratory of Separation and Reaction Engineering - Laboratory of Catalysis and Materials (LSRE-LCM), Polytechnic Institute of Bragança, Campus de Santa Apolónia, \\ 5300-253 Bragança, Portugal
}

\section{A R T I C L E I N F O}

\section{Keywords:}

Hibiscus sabdariffa L. calyces

Delphinidin-3-O-sambubioside

Cyanidin-3-O-sambubioside

Heat-/ultrasound-assisted extraction

Process optimization

Natural colorants

\begin{abstract}
A B S T R A C T
Heat- and ultrasound-assisted extraction methods were applied to recover anthocyanins from Hibiscus sabdariffa calyces. The extraction variables, time $(t)$, ethanol proportion $(S)$, and temperature $(T)$ or ultrasonic power $(P)$, were combined in a 5-level experimental design and analysed by response surface methodology for process optimization. The delphinidin-3-O-sambubioside $(C 1)$ and cyanidin-3-O-sambubioside $(C 2)$ levels were monitored by LC-DAD-ESI/MS ${ }^{\mathrm{n}}$ and used as response criteria. The developed models were successfully fitted to the experimental data and used to determine optimal extraction conditions. UAE was the most efficient method yielding $51.76 \mathrm{mg} \mathrm{C1}+C 2 / \mathrm{g}$ R under optimal conditions $(t=26.1 \mathrm{~min}, P=296.6 \mathrm{~W}$ and $S=39.1 \%$ ethanol, v/ v). The dose-response effects of the solid/liquid ratio on the extraction rate were also determined. The anthocyanin levels herein reported are higher than those found in the literature, which support the potential use of $H$. sabdariffa as a sustainable source of natural colorants with application in different industrial sectors.
\end{abstract}

\section{Introduction}

The globalization of the industrial food sector, together with consumer's awareness about the existence of bio-based alternatives to the artificial additives, nowadays massively used, and with potential toxic effects in humans, has promoted the demand for food products formulated with natural ingredients recovered from plant materials (Carocho, Morales, \& Ferreira, 2015; Martins, Roriz, Morales, Barros, \& Ferreira, 2016). The scientific research in this area has gained international prominence (Almeida et al., 2018; Carocho et al., 2016; Pinela et al., 2017), as it is still necessary to expand the range of natural options and find new sources (e.g., plants, algae and insects), as well as to develop sustainable processes for an efficient recovery of the target compounds (e.g., anthocyanins, carotenoids, and beet derivatives).

The global food colouring market has grown rapidly in recent years and it is expected to continue growing by $10 \%$ to $15 \%$ annually (Carle \& Schweiggert, 2016). The colour, in addition to be an important food sensory attribute, often related to flavour, safety and overall quality, also greatly influences product's marketing success. At the same time, there is a growing interest in replacing the artificially obtained colorants by natural counterparts, since the former have been associated with adverse health effects, including hyperkinesis, skin rashes, tumours, kidney damage and migraine, among others (Ramesh \& Muthuraman, 2018). Natural colorants can also provide an extensive range of colours, with the advantage of being innocuous and can provide beneficial health effects (Castañeda-Ovando, Pacheco-Hernández, Páez-Hernández, Rodríguez, \& Galán-Vidal, 2009). However, the high stability and low cost of the synthetic food colorants have limited the use of the natural counterparts by the industrial sector (Carocho et al., 2015). Moreover, there are only few natural alternatives approved by federal authorities (Martins et al., 2016).

Plants are an interesting source of natural pigments endowed with colouring potential and bioactivities (Jabeur et al., 2017). Among them, Hibiscus sabdariffa L. (Fam. Malvaceae), also known as roselle, is an annual medicinal shrub relatively easy to grow and used worldwide by the food and pharmaceutical industries (Da-Costa-Rocha, Bonnlaender, Sievers, Pischel, \& Heinrich, 2014). It comprises two main varieties, the altissima Wester, cultivated for the jute-like fibre, and the sabdariffa, generally pigmented and cultivated for the edible calyces used in the preparation of herbal teas and beverages, and a number of pastry products (Sharma et al., 2016). In folk medicine, H. sabdariffa calyx infusions are used for their diuretic, febrifugal and hypotensive effects,

\footnotetext{
* Corresponding author.

E-mail address: iferreira@ipb.pt (I.C.F.R. Ferreira).
} 
and for helping to lower body temperature; while other preparations are used for treating sore throats and coughs, liver, cardiac and nerve diseases, and genital problems (Da-Costa-Rocha et al., 2014). Some of these traditional uses have been validated by scientific studies, which have shown that calyx extracts have strong antioxidant and antihypertensive capacities, together with antihypercholesterolaemic, antinociceptive, and antipyretic effects, among others (Ali, Al Wabel, \& Blunden, 2005; Da-Costa-Rocha et al., 2014). Therefore, this plant has high potential to be used in the development of new functional and therapeutic products.

Most of the phytochemical studies on the $H$. sabdariffa constituents have been directed towards the characterization of pigments, namely anthocyanins (Ali et al., 2005; Beye, Hiligsmann, Tounkara, \& Thonart, 2017; Jabeur et al., 2017). Delphinidin-3-glucoside, cyanidin-3-glucoside, and in particular delphinidin-3-sambubioside (hibiscin) and cyanidin-3-sambubioside (gossypicyanin) have been identified in calyx extracts (Alarcón-Alonso et al., 2012; Beye et al., 2017; SalazarGonzález, Vergara-Balderas, Ortega-Regules, \& Guerrero-Beltrán, 2012). These anthocyanins are responsible for the characteristic red colour of the $H$. sabdariffa calyces and can be recovered for subsequent use as colorants in different industrial sectors.

In order to turn bio-based colorants into real and efficient alternatives to the widely used artificial analogues, it is necessary to find promising sources for their extraction and develop sustainable recovery processes. Today, several technologies are available to enhance extraction, including ultrasounds (López et al., 2018), microwaves (Liazid, Guerrero, Cantos, Palma, \& Barroso, 2011), pulsed electric fields, and pressurized and supercritical fluids (Corrales, Toepfl, Butz, Knorr, \& Tauscher, 2008; Garcia-Mendoza et al., 2017). Among them, ultrasound-assisted extraction (UAE) brings significant benefits over conventional heating methods in terms of time and solvent consumption and extraction yield (Chemat et al., 2017a; Marić et al., 2018). This "green" processing technique also reduces energy and water consumption, allows recycling of by-products through bio-refining, and ensures a safe and high quality product (Chemat et al., 2017a). In addition, UAE has been recognised as suitable for industrial applications (Vilkhu, Mawson, Simons, \& Bates, 2008). However, the efficiency of these processes is affected by process variables (e.g., time, temperature, ultrasonic power and solvent). Therefore, it is necessary to use appropriate experimental designs and optimization tools to determine the optimal extraction conditions leading to the best responses in terms of recovering of target compounds.

This study was performed aiming at optimizing the recovery of the two major anthocyanins found in $H$. sabdariffa calyces by heat- and ultrasound-assisted extraction processes to serve as natural colorants (a workflow scheme is presented in Fig. A1). The three most relevant independent variables for each process were combined in a circumscribed central composite design, and response surface methodology (RSM) was used for process optimization. It is thus intended to identify which method and extraction conditions are the most suitable to extract these colouring compounds.

\section{Material and methods}

\subsection{Plant material}

Dried flowers of $H$. sabdariffa were supplied by a local company (Pragmático Aroma Lda, Alfândega da Fé, Bragança, Portugal) that produces medicinal and aromatic plants with organic certification. According to the producers, the plant material was dehydrated in a drying chamber with controlled conditions of temperature, relative humidity and air velocity, in order to ensure the quality of the final product. The red flower calyx consisting of 5 large sepals with a collar (epicalyx) of 8 to $12 \mathrm{slim}$, pointed bracts (or bracteoles) around the base was handpicked and reduced to a fine powder $(\sim 20 \mathrm{mesh})$. The powdered samples were kept at $-80^{\circ} \mathrm{C}$ until further use.

\subsection{Extraction methods}

\subsubsection{Heat-assisted extraction}

The heat-assisted extraction (HAE) was performed in a thermostated water bath using sealed vessels to avoid solvent evaporation. The dry powder samples $(0.6 \mathrm{~g})$ were mixed with $20 \mathrm{~mL}$ of solvent (ethanol:water mixtures) and processed under continuous electromagnetic stirring according to the experimental design presented in Table A1. The extraction time ( $\mathrm{t}, 55-150 \mathrm{~min})$, temperature $\left(T, 20-90^{\circ} \mathrm{C}\right)$ and ethanol proportion $(S, 0-100 \%)$ were the considered independent variables. The solid/liquid ratio $(S / L)$ was kept constant $(30 \mathrm{~g} / \mathrm{L})$. After extraction, the mixture was centrifuged $(6000 \mathrm{rpm}$ for $10 \mathrm{~min}$ at room temperature) and the supernatant filtered through Whatman filter paper No. 4.

\subsubsection{Ultrasound-assisted extraction}

The ultrasound-assisted extraction (UAE) was performed using an ultrasonic equipment (QSonica sonicators, model CL-334, Newtown, CT, USA). The dry powder samples $(1.5 \mathrm{~g})$ were placed in a beaker with $50 \mathrm{~mL}$ of solvent (ethanol: water mixtures) and processed according to the experimental design presented in Table A1. The extraction time ( $\mathrm{t}$, $3-36.5 \mathrm{~min})$, ultrasonic power $(P, 100-500 \mathrm{~W}$; at a frequency of $20 \mathrm{kHz})$ and ethanol proportion ( $S$ 0-100\%) were the considered independent variables. The solid/liquid ratio $(S / L, 30 \mathrm{~g} / \mathrm{L})$ and the temperature $\left(30-35^{\circ} \mathrm{C}\right)$ were kept constant during extraction. Then, the mixtures were centrifuged ( $6000 \mathrm{rpm}$ for $10 \mathrm{~min}$ at room temperature) and the supernatant was filtered through Whatman filter paper No. 4.

A probe system was used for extraction because it delivers the ultrasonic intensity on a small surface compared to an ultrasonic bath, thus being more powerful and widely used for sonication of small volumes of sample (Chemat et al., 2017a; Sicaire et al., 2016). The probe was immersed directly into the reaction beaker (containing the solvent and the sample) so that less attenuation could happen. A special care was taken because of the fast rise of the temperature in the reaction system.

\subsection{Determination of extraction yield}

The residue or extract weight resulting from each extraction was determined gravimetrically using crucibles, subjected firstly to a partial evaporation of the water at $60^{\circ} \mathrm{C}$ and then to heat treatment at $100{ }^{\circ} \mathrm{C}$ for $24 \mathrm{~h}$. The results were expressed in percentage $(\%, \mathrm{w} / \mathrm{w})$.

\subsection{Chromatographic analysis of anthocyanins}

Each obtained solution was subjected to solvent evaporation at $35^{\circ} \mathrm{C}$ and the obtained residue redissolved in water and filtered through a $0.22-\mathrm{m}$ disposable LC filter disk. The chromatographic analysis was performed in a Dionex Ultimate 3000 UPLC system (Thermo Scientific, San Jose, CA, USA) equipped with a diode array detector coupled with an electrospray ionization mass detector (LC-DAD-ESI/MS ${ }^{\mathrm{n}}$ ), as previously described by Jabeur et al. (2017). Detection was carried out with a DAD (520 $\mathrm{nm}$ as the preferred wavelength) and a MS (Linear Ion Trap LTQ XL mass spectrometer, Thermo Finnigan, San Jose, CA, USA) equipped with an ESI source, working in positive mode. The anthocyanins were characterized according to their UV-Vis and mass spectra, and quantification was performed through a calibration curve performed using cyanidin-3-glucoside standard $(\mathrm{y}=243287 \mathrm{x}$ - 1E6; $R^{2}=0.995$ ). The results were expressed as $\mathrm{mg} / \mathrm{g}$ of plant material (P) or residue $(\mathrm{R})$.

\subsection{Extraction optimization by response surface methodology}

\subsubsection{Experimental design}

A five-level circumscribed central composite design (CCCD) with three independent variables $\left[X_{1}(\mathrm{t}, \mathrm{min}), X_{2}\left(T,{ }^{\circ} \mathrm{C}\right.\right.$ or $\left.P, \mathrm{~W}\right)$ and $X_{3}(S$, 
\%)] was applied to optimize the extraction of anthocyanins from $H$. sabdariffa calyces by HAE and UAE. The CCCD included 14 independent combinations and 6 replicates at the centre of the experimental design, chosen to maximize the predictive capacity of the models. In addition, the experimental points were generated on a sphere around the centre point to ensure that the variation of the model prediction is constant for all points equidistant from the centre. The experimental runs were randomized to minimize the effect of unexpected variability in the observed responses.

\subsubsection{Response criteria used to understand the extraction behaviour}

The extraction yield and levels of delphinidin-3-O-sambubioside (C1) and cyanidin-3-O-sambubioside ( $C 2$ ), as well as the total amount resulting from the sum of both compounds $(C T)$, were the four response variables considered for the RSM optimization. In addition, the anthocyanin content was expressed using the $Y_{1}(\mathrm{mg} / \mathrm{g} \mathrm{P} \mathrm{dw})$ and $Y_{2}(\mathrm{mg} /$ $\mathrm{g} \mathrm{R}$ ) response formats in order to determine the concentration present in the dried plant material and in the obtained residue or extract, respectively.

\subsubsection{Mathematical model}

The response surface models were fitted by means of least squares calculation using the following second-order polynomial equation:

$Y=b_{0}+\sum_{i=1}^{n} b_{i} X_{i}+\sum_{\substack{i=1 \\ j>1}}^{n=1} \sum_{j=2}^{n} b_{i j} X_{i} X_{j}+\sum_{i=1}^{n} b_{i i} X_{i}^{2}$

where $Y$ is the dependent (response) variable to be modelled, $X_{i}$ and $X_{j}$ define the independent variables, $b_{o}$ is the constant coefficient, $b_{i}$ the coefficient of the linear effect, $b_{i j}$ the coefficient of the interaction effect, $b_{i i}$ the coefficient of the quadratic effect, and $n$ is the number of variables.

\subsubsection{Procedure to optimize the variables to a maximum response}

The maximization of the model-produced responses was achieved using a simple method tool to solve non-linear problems (Heleno et al., 2016; Pinela et al., 2016). Limitations were made to the variable coded values to avoid unnatural conditions (i.e., time $<0$ ).

\subsection{Dose-response analysis of the solid/liquid ratio effect}

After optimizing the experimental conditions for the variables $X_{1}, X_{2}$ and $X_{3}$, the solid/liquid ratio $(S / L, \mathrm{~g} / \mathrm{L})$ was included as the fourth variable $\left(X_{4}\right)$ to be optimized in order to design more productive and sustainable processes, as demanded by the industrial sector. The response effects as function of the $S / L$ variation showed linear trends and were depicted using a general linear equation with intercept $(Y=b+m \cdot S / L)$, where $Y$ is the used response criteria (i.e. if $Y_{1}$ the units would be $\mathrm{mg} / \mathrm{g} \mathrm{P} \mathrm{dw}$ ) and $b$ and $m$ are the parameters (intercept and slope, respectively). The rate of the process parameter ( $m$, if assessing the $Y_{1}$ response criterion the units would be $\mathrm{mg} / \mathrm{g}$ P per $\mathrm{g} / \mathrm{L}$ ) provides information related to the extraction as function of $S / L$ increase. Positive values will indicate an increase in the extraction responses, whereas negative values will designate a decrease in the extraction efficiency, as the $S / L$ increase.

\subsection{Fitting procedures and statistical analysis}

The statistical analysis of the experimental results and models fitting was performed in three steps, using a Microsoft Excel spreadsheet, as follows:

(1) The measurement of the coefficients was achieved using the nonlinear least-square (quasi-Newton) method provided by the macro "Solver" (Kemmer \& Keller, 2010), by minimization of the sum of the quadratic differences between the observed and model-predicted values.

(2) The significance of the coefficients was obtained via "SolverAid" macro (de Levie, 2012) to determine the parametric confidence intervals. The terms that were not statistically significant ( $p$ value $>0.05$ ) were excluded to simplify the model.

(3) The model reliability was confirmed by applying the following criteria: (a) the Fisher $F$-test ( $\alpha=0.05$ ) was used to determine the consistency of the constructed models to describe the obtained data (Shi \& Tsai, 2002); (b) the "SolverStat" macro was used to make an assessment of the parameter and model prediction uncertainties (Comuzzi, Polese, Melchior, Portanova, \& Tolazzi, 2003); (c) $\mathrm{R}^{2}$ was determined to explain the variability proportion of the dependent variable obtained by the model.

\section{Results and discussion}

\subsection{Experimental data for RSM optimization}

Although some previous studies on the extraction of anthocyanins from $H$. sabdariffa calyces can be found in literature, no reports detailing the optimal conditions maximizing their extraction are presently available. In addition, the compositional diversity of anthocyanins' natural sources (e.g., fruits, flowers, leaves, stems and roots) does not allow to directly extrapolate the extraction conditions of these pigments from previously studied sources. Therefore, it is important to conduct independent studies to maximize the extraction of anthocyanins from H. sabdariffa, by selecting the relevant variables for each selected extraction method. Table 1 provides a bibliographical summary of the delphinidin-3-O-sambubioside, cyanidin-3-O-sambubioside and total anthocyanin levels in $H$. sabdariffa and other major plant sources, as well as the conditions used for their extraction. Although important conclusions can be derived from this summary, the results may be highly dependent on dissimilarities not foreseen in these studies, where certain variables remaining constant, together with raw-material's variability, can definitely influence the extraction process. Therefore, the first approach to optimize the efficiency of the HAE and UAE processes to recover anthocyanins from $H$. sabdariffa calyces consisted of the application of RSM coupled to a CCCD design with five levels of variation for the three independent variables as follows: $t(30-150 \mathrm{~min})$, $T\left(30-90^{\circ} \mathrm{C}\right)$ and $S(0-100 \%)$ for HAE and $t(3-45 \mathrm{~min}), P(100-500 \mathrm{~W})$ and $S(0-100 \%)$ for UAE. A detailed description of the coded and natural values of the selected variables for each extraction method in the CCCD design is presented in Table A1. The different steps carried out in this optimization study are illustrated in Fig. A1.

According to previous studies, high $P$ can cause major alterations in plant materials by inducing greater shear forces, which result from the oscillation and collapse of cavitation bubble within the solvent. As a consequence, critical temperature and pressure are generated, inducing the formation of free radicals that can attack target metabolites and lead to their degradation (Chemat et al., 2017; Meullemiestre, Breil, Abert-Vian, \& Chemat, 2016). However, this independent variable was optimized in order to apply the minimum power required to achieve the best results.

The experimental values obtained under the 20 runs of the five-level CCCD design applied to the HAE and UAE processes used in the recovery of anthocyanins from $H$. sabdariffa calyces are presented in Table 2. The different response criteria used (yield, $Y_{1}$ and $Y_{2}$ ) are of interest for industrial sectors dealing with the recovering of high addedvalue compounds from plant materials to be used as natural colorants, or other bio-based ingredients, providing information concerning the amount of plant material needed to obtain a certain quantity of the target compounds, and the concentration of these compounds in the produced extracts.

The extraction yield ranged from 34.45 to $62.80 \%$ and $14.38-56.21 \%$ for HAE and UAE, respectively (Table 2 ). In both cases, 


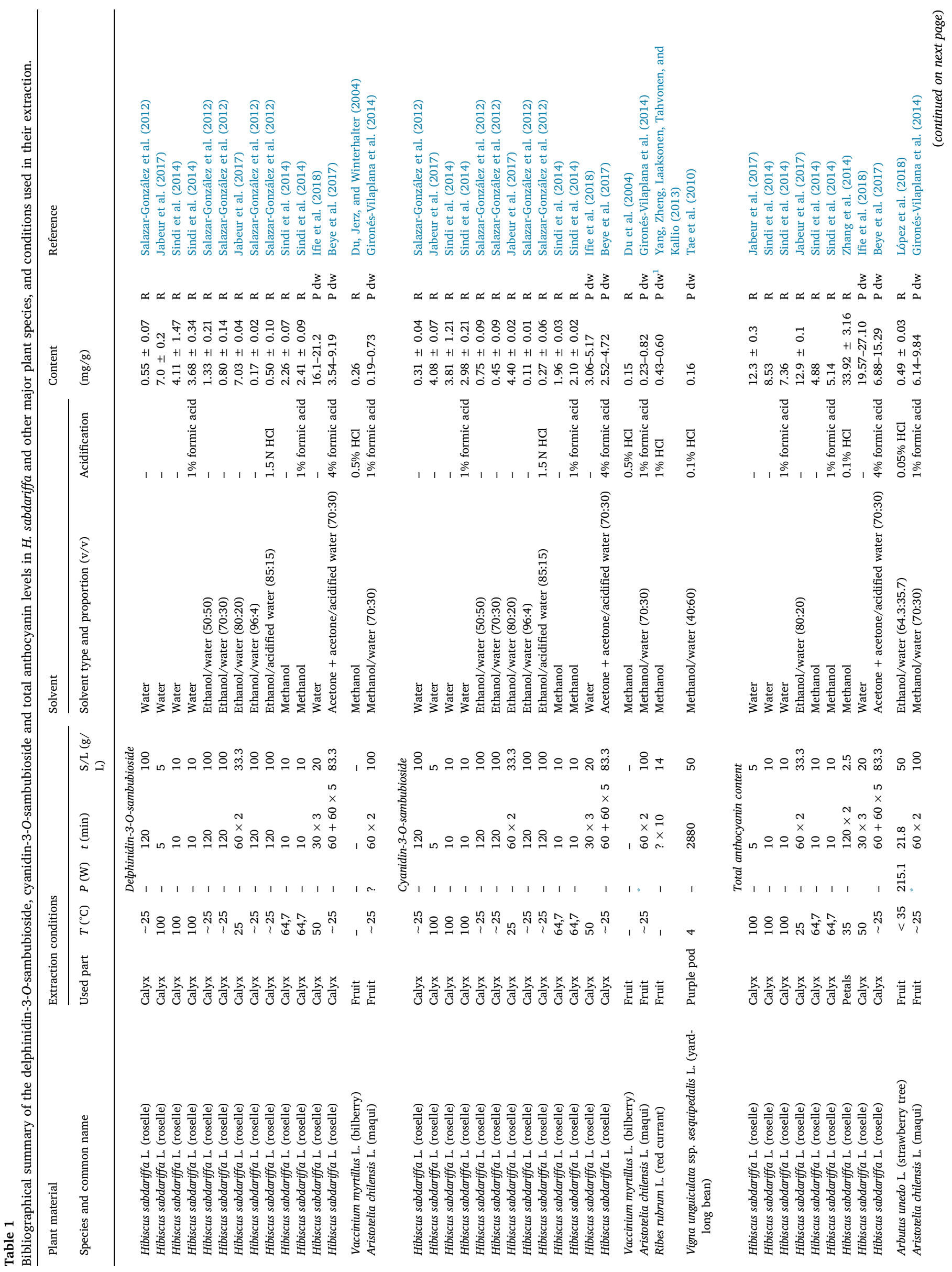


the higher values were achieved with the run 12 , which combined the following conditions: $t=90 \mathrm{~min}, T=90^{\circ} \mathrm{C}$ and $S=50 \%$ for HAE, and $t=24 \mathrm{~min}, T=500 \mathrm{~W}$ and $S=50 \%$ for UAE. In general, HAE originated the highest experimental yields, translated in higher amounts of residue or crude extract. A lower yield (28.3\%) was obtained by Alarcón-Alonso et al. (2012) when using water at $55^{\circ} \mathrm{C}$ with $2 \mathrm{~h}$ of extraction.

As described by other authors (Ifie, Ifie, Ibitoye, Marshall, \& Williamson, 2018; Jabeur et al., 2017; Sindi, Marshall, \& Morgan, 2014), $C 1$ predominated over $C 2$ in all cases (Table 2), with levels ranging from $1,02-6.88 \mathrm{mg} / \mathrm{g} \mathrm{P}$ and $0.43-2.11 \mathrm{mg} / \mathrm{g} \mathrm{P}$ for HAE and from 1.26 to $14.31 \mathrm{mg} / \mathrm{g} P$ and $0.92-7.29 \mathrm{mg} / \mathrm{g} P$ for UAE, respectively. The highest total content $(C T)$ was achieved with the runs $13(8.99 \mathrm{mg} /$ $\mathrm{g} \mathrm{P})$ and $10(21.48 \mathrm{mg} / \mathrm{g} \mathrm{P}$ ) of the HAE and UAE processes, respectively. Beye et al. (2017) recovered up to $9.19 \mathrm{mg} \mathrm{C1/g} \mathrm{P}$ and $4.72 \mathrm{mg} \mathrm{C2/g} \mathrm{P}$ from dried calyces of $H$. sabdariffa cultivars grown in Senegal, when subjected to a 60-min extraction with acetone followed by five more 60min extraction cycles with acetone/acidified water (70:30, v/v; 4\% formic acid). Higher levels of $C 1$ (up to $21.2 \mathrm{mg} / \mathrm{g}$ P), but lower of $C 2$ (up to $5.17 \mathrm{mg} / \mathrm{g}$ P) were obtained by Ifie et al. (2018) in dried calyces of a dark red variety of $H$. sabdariffa cultivated in Ibadan, South-Western Nigeria, in comparison with the quantities found in our samples harvested in north-eastern Portugal. These contents were obtained by three successive aqueous extractions of 30 -min duration at $50^{\circ} \mathrm{C}$.

The CT content in the obtained residue ranged from 3.41 to $12.44 \mathrm{mg} / \mathrm{g} \mathrm{R}$ and $14.39-47.93 \mathrm{mg} / \mathrm{g}$ R for HAE and UAE, respectively (Table 2). In general, these levels are higher than those found in the literature (Table 1). Salazar-González et al. (2012) obtained up to $2.08 \mathrm{mg} \mathrm{CT} / \mathrm{g} \mathrm{P}(1.33 \mathrm{mg} \mathrm{C1} / \mathrm{g}$ and $0.75 \mathrm{mg} \mathrm{C} / \mathrm{g})$ when performing a 120 -min extraction with ethanol:water mixtures $(50: 50, \mathrm{v} / \mathrm{v})$ at a $S / L$ of $100 \mathrm{~g} / \mathrm{L}$ and room temperature. Up to $7.92 \mathrm{mg} \mathrm{CT} / \mathrm{g} \mathrm{R}(4.11 \mathrm{mg} \mathrm{C1/g}$ and $3.81 \mathrm{mg} \mathrm{C2/g}$ ) were achieved by Sindi et al. (2014) with aqueous extractions of $10 \mathrm{~min}$ at $100^{\circ} \mathrm{C}$. In another study, Jabeur et al. (2017) quantified $11.08 \mathrm{mg} / \mathrm{g} \mathrm{R}\left(7.0 \mathrm{mg} \mathrm{C1}+4.08 \mathrm{mg} C_{2}\right)$ in extracts obtained by addition of boiling water (at $100{ }^{\circ} \mathrm{C}$ ) to the samples and subsequent maceration for $5 \mathrm{~min}$ at room temperature (process known as infusion).

\subsection{Theoretical response surface models}

The parametric values obtained by fitting the response values (Table 2) to the second-order polynomial model of Eq. (1) using a nonlinear algorithm are presented in Table A2 (Eqs. (2)-(15)). These values translate the response patterns and are useful for developing mathematical models (Table A3), which indicate the complexity of the possible scenarios. However, not all Eq. (1) parameters were used in the development of the models since some coefficients were non-significant $(n s)$; the significant ones were assessed at a 95\% confidence level $(\alpha=$ $0.05)$. The statistic lack-of-fit, used to test the adequacy of the obtained models, revealed that no considerable improvement was achieved by the inclusion of the statistically $n s$ parametric values. The agreement between the experimental and predicted values provided an acceptable explanation of the obtained results (Table 2). Additionally, residues were randomly scattered around zero and no grouped data or autocorrelations were observed. The obtained coefficients of determination $\left(R^{2}\right)$ were higher than 0.94 and 0.86 in the cases of HAE and UAE, respectively (Table A2), which indicates that the variability of each response can be explained by the independent variables involved in the process. Therefore, the models proved to be applicable and were used in the later prediction and optimization steps. Although the obtained model coefficients are empirical and cannot be associated with physical or chemical significance, they are useful to predict the outcome of untested experimental conditions (Ranic et al., 2014). Moreover, the sign of the parametric values determines part of the response; for positive effects, the response is higher at the high level, and when a factor has a negative effect, the response is lower at the high level. The higher of the parametric value, the more significant the weight of the 


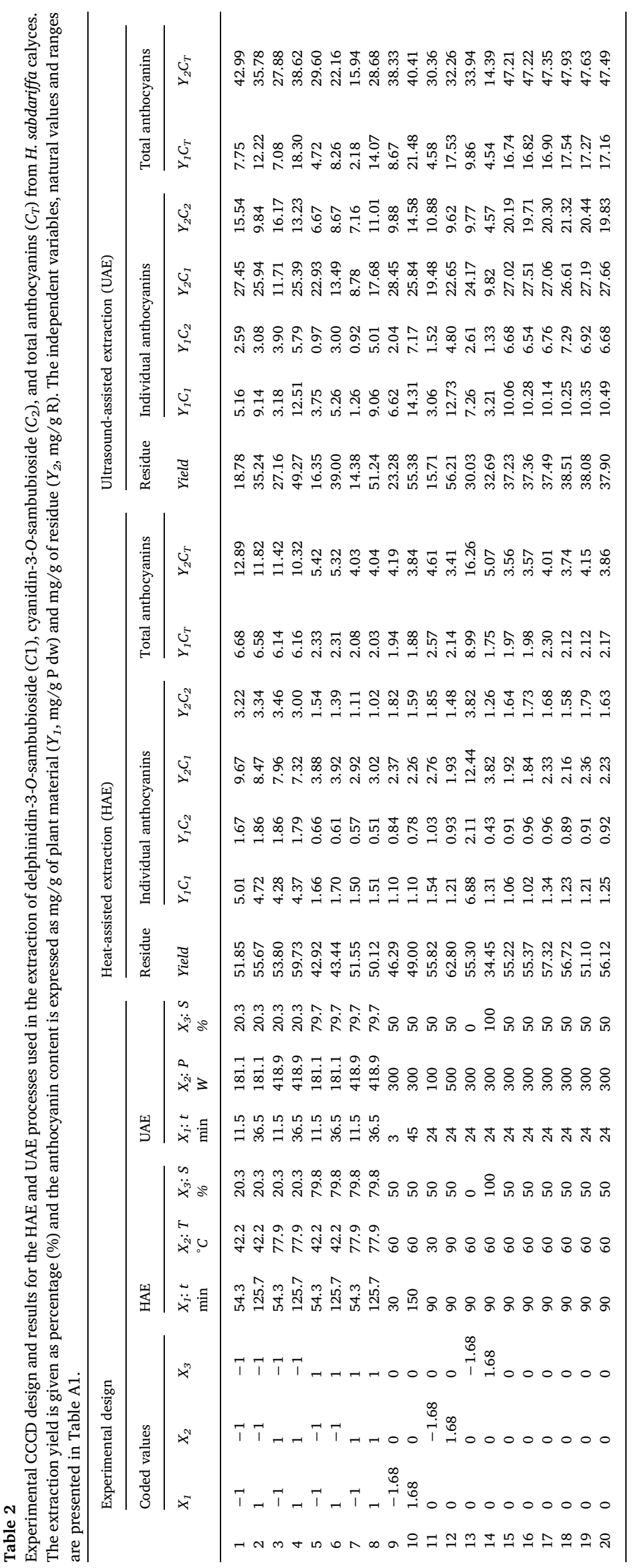


governing variable is.

Certain features regarding the overall effects of the independent variables were inferred from the complexity of the parametric values, i.e. the variables were ordered in a decreasing form as a function of its significance in the extraction processes as follows: $S>>T>t$ for HAE; $S>P>t$ for the $Y_{2}$ response formats of UAE; and $t>P>S$ for the extraction yield of UAE. It was also possible to observe that all the evaluated responses were significantly affected by linear and quadratic effects, whose values were particularly higher for the variable $S$ (with some exceptions, since, although the linear effects of the variable $t$ were negligible in most cases in the HAE process, the corresponding values for the $Y_{1}$ response formats and extraction yield in the UAE process were quite high). The parametric values also revealed that strong interactions occurred in the UAE process, mainly between the variables $t \times P$. In turn, the interactions $t \times T$ and $P \times S$ were of minor relevance in the HAE and UAE processes, respectively. These results justify the use of RSM as an optimization tool, since one-variable-at-atime approaches do not allow to assess the existence of interactive effects, which makes it difficult to determine optimum values.

To make all these combined effects more explicit and to visually describe the extraction trends, the results were presented in the response surface graphs discussed below.

\subsection{Response surface analysis: Efficiency of the extraction conditions and methods}

Fig. 1 shows the 3D response surface graphs of the extraction yield (residue) and total anthocyanin content (expressed in terms of $\mathrm{mg} / \mathrm{g}$ of plant material $\left(Y_{1}\right)$ and $\mathrm{mg} / \mathrm{g}$ of residue $\left(Y_{2}\right)$ ) obtained for both extraction methods (HAE and UAE). The net surfaces were predicted with the second-order polynomial model of Eq. (1), whose model equations are presented in Table A3. The binary actions between the variables are displayed when the excluded variable is positioned at the centre of the experimental domain (Table A1). Additionally, the goodness of fit of the model is illustrated by the ability to simulate response changes between the observed and predicted data, and the residual distribution as a function of each variable. In turn, Fig. 2 shows the 2D contour graphs resulting from the projections of the $3 \mathrm{D}$ response surfaces in the $\mathrm{XY}$ plane. These projections focused the optimal extraction conditions obtained for the residue (yield), delphinidin-3-O-sambubioside (C1) and cyanidin-3-O-sambubioside (C2), depending on the used extraction method. For each anthocyanin, the result is expressed in terms of $\mathrm{mg} / \mathrm{g}$ of plant material $\left(Y_{1}\right)$ and $\mathrm{mg} / \mathrm{g}$ of residue $\left(Y_{2}\right)$ to visually describe the extraction trends. The binary actions between variables are displayed when the excluded variable is positioned at the individual optimum (Table 3).

\subsubsection{Extraction yield}

After analysing the response surface and contour graphs shown in Figs. 1 and 2, it was possible to draw some conclusions regarding the effects of the independent variables on the extraction yield. For HAE, the variable $S$ originated the most marked curvatures on the net surfaces, followed by the variable $t$. In the first case, the extraction was promoted with the increase in ethanol proportion up to $35 \%$ with subsequent decrease. The variable $t$ had a comparable behaviour, since the medium-long extraction times were the most suitable ones. In turn,
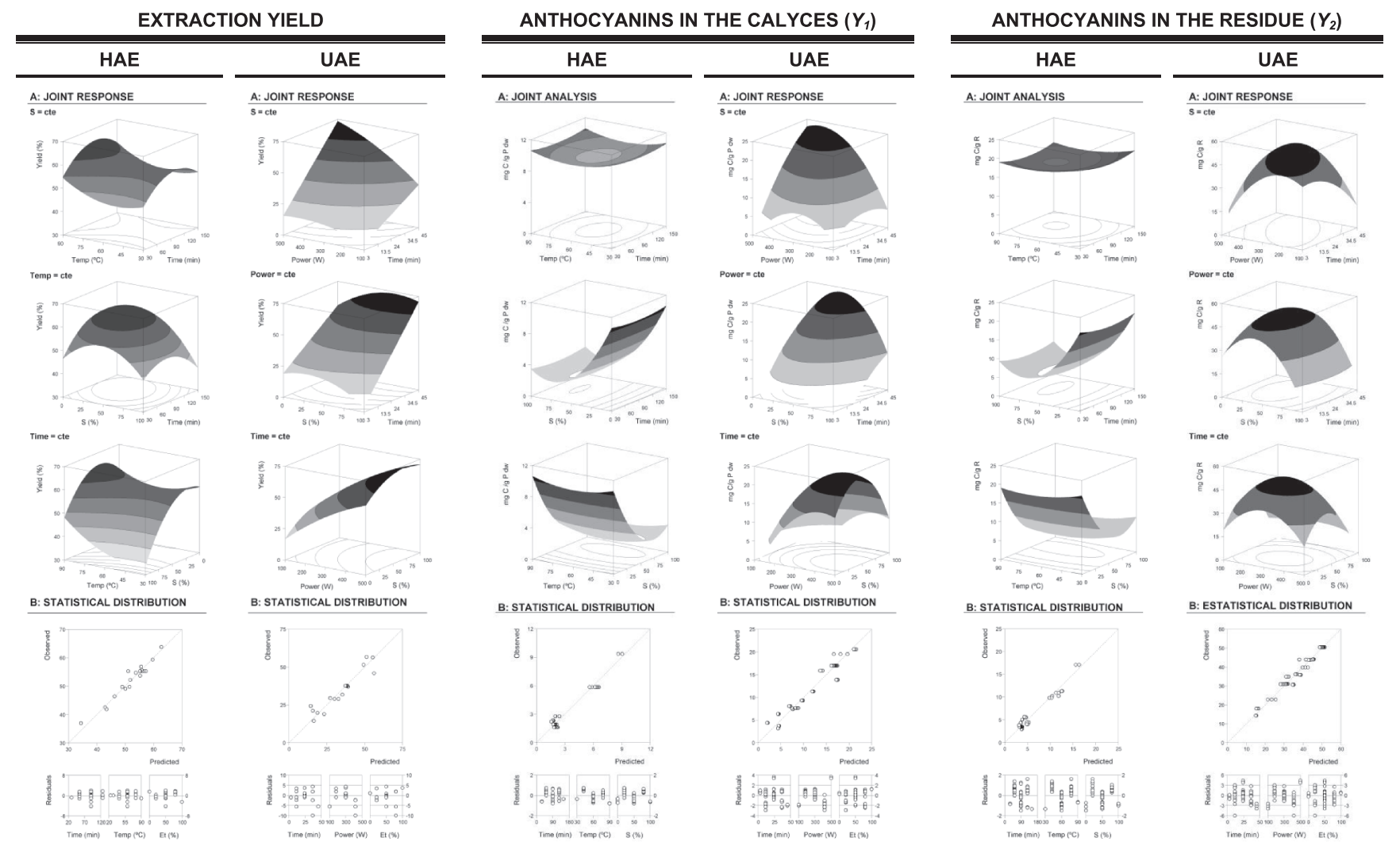

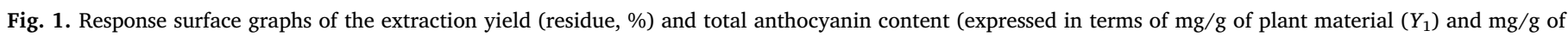

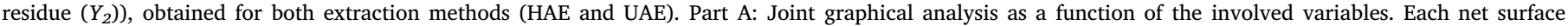

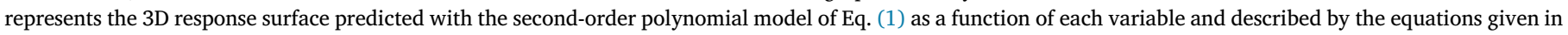

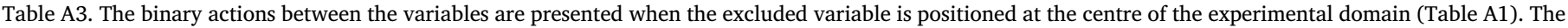

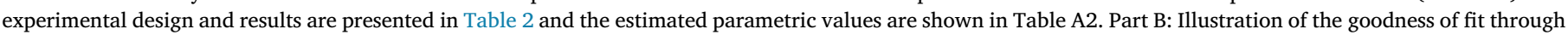

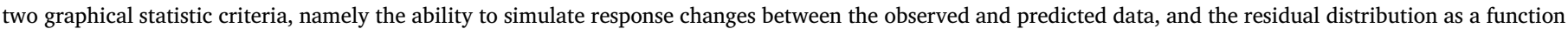
of each variable. 

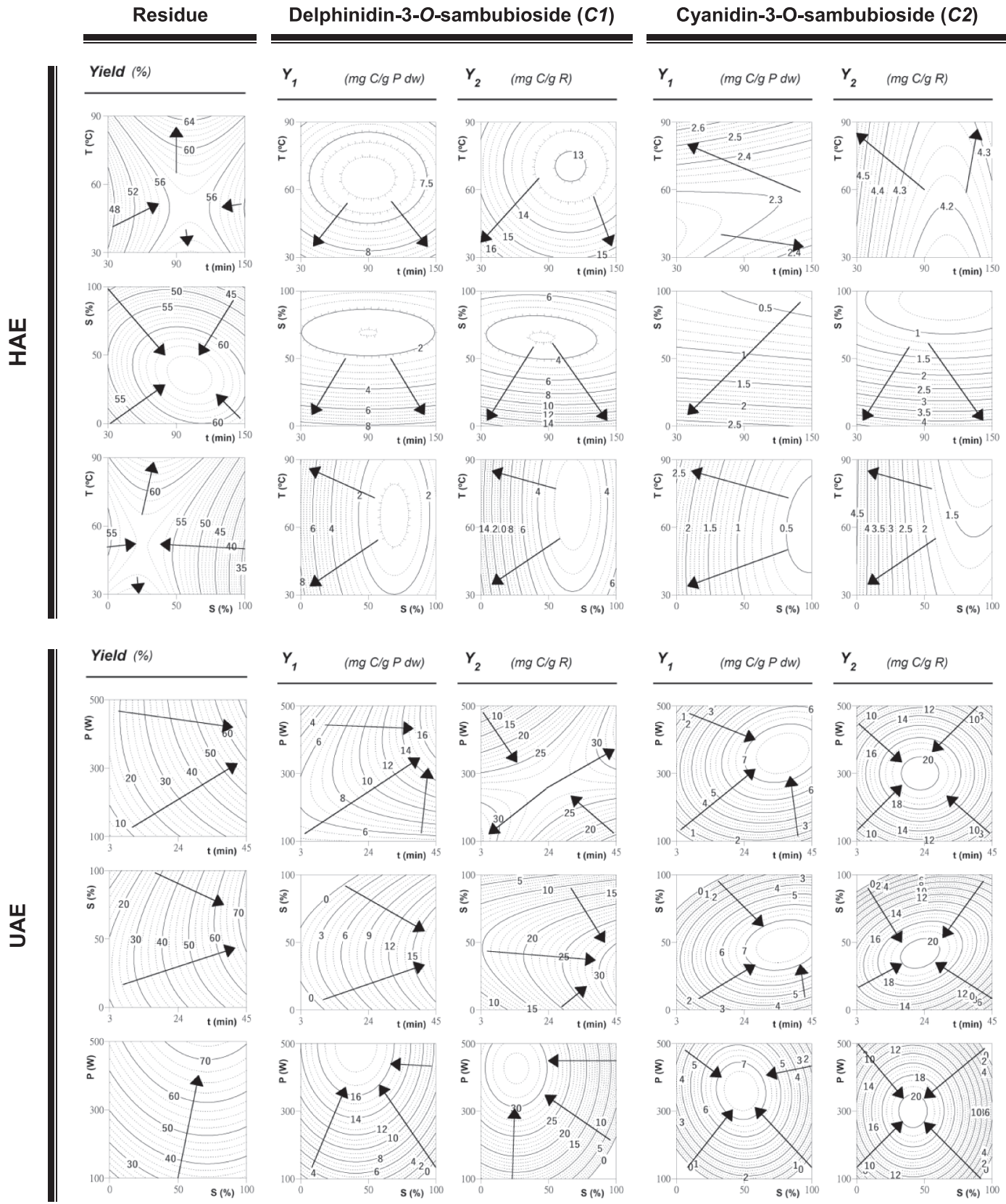

Fig. 2. 2D contour graphs focusing the optimal points for the extraction yield (residue) and levels of delphinidin-3-O-sambubioside (C1) and cyanidin-3-O-sambubioside (C2) obtained by HAE and UAE. For each anthocyanin, the result is expressed in terms of $\mathrm{mg} / \mathrm{g}$ of plant material $\left(Y_{1}\right)$ and $\mathrm{mg} / \mathrm{g}$ of residue $\left(Y_{2}\right)$ to visually describe the extraction trends. Each contour graph represents the projection of the theoretical 3D response surface predicted by the second-order polynomial model of Eq. (1) in the XY plane. The binary actions between variables are presented when the excluded variable is positioned at the individual optimum (Table 3). The experimental design and results are presented in Table 2 and the estimated parametric values are shown in Table A2.

higher $T$ provided the highest extraction yields. The amount of residue was also affected by the interaction of the variable $S$ with $t$ (negative interaction) and $T$ (positive interaction) (Table A2). In the UAE process, the most marked response surface curvatures were caused by the tested ranges of $t$ and $P$, whose increase led to the higher extraction yields (Table A2). Additionally, the obtained yield was also promoted by the strong positive interaction between $t$ and the other two variables (Table A2). Therefore, based on the optimal extraction conditions presented in Table 3, it was observed that HAE required a longer $t$ and a lower $S$ than UAE (while both methods required the highest tested $T$ or $P$ ) to obtain optimum response values. The best yield $(73.30 \pm 4.51 \%)$ was obtained with the UAE process under the following conditions: $t=45.0 \mathrm{~min}, P=500.0 \mathrm{~W}$, and $S=71.4 \%$ ethanol, $\mathrm{v} / \mathrm{v}$. Comparable results were obtained by López et al. (2018) when optimizing the HAE and UAE of anthocyanins from Arbutus unedo fruits, as they also associated the highest extraction yields with UAE process.

\subsubsection{Anthocyanin contents}

The variable $S$ was the one that affected most the HAE of anthocyanins from $H$. sabdariffa calyces (Table A2), as verified from the obtained extraction yield with this method. Its significance is visually highlighted in the response surface graphs (Fig. 1), which show that the 
Table 3

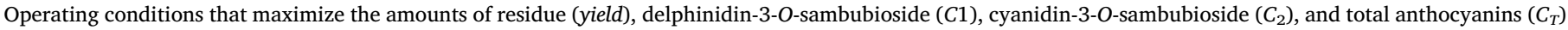
extracted from $H$. sabdariffa calyces as a function of the extraction method (HAE and UAE) and response value format ( $Y_{1}$, mg/g $\mathrm{P}$, and $Y_{2}$, mg/g R).

\begin{tabular}{|c|c|c|c|c|c|c|c|c|}
\hline \multirow[t]{2}{*}{ Criteria } & & & \multicolumn{3}{|c|}{ Optimal extraction conditions } & \multicolumn{3}{|c|}{ Response optimum } \\
\hline & & & $X_{1}: t(\min )$ & $X_{2}: T\left({ }^{\circ} C\right)$ or $P(W)$ & $X_{3}: S(\%)$ & & & \\
\hline \multicolumn{9}{|c|}{ (A) Individual optimal extraction conditions } \\
\hline \multirow[t]{7}{*}{ HAE } & Yield & & 101.5 & 90.0 & 35.4 & 64.74 & \pm 3.60 & $\%$ \\
\hline & $Y_{1}$ & $C 1$ & 30.0 & 30.0 & 0.0 & 8.57 & \pm 2.07 & $m g C 1 / g P d w$ \\
\hline & & $C 2$ & 30.0 & 90.0 & 0.0 & 2.66 & \pm 1.15 & $m g C 2 / g P d w$ \\
\hline & & $C T$ & 30.0 & 30.0 & 0.0 & 10.61 & \pm 3.26 & $m g C T / g P d w$ \\
\hline & $Y_{2}$ & $C 1$ & 30.0 & 30.0 & 0.0 & 16.81 & \pm 2.37 & $m g C 1 / g R$ \\
\hline & & $C 2$ & 30.0 & 90.0 & 0.0 & 4.59 & \pm 1.24 & $m g C 2 / g R$ \\
\hline & & $C T$ & 30.0 & 30.0 & 0.0 & 20.86 & \pm 1.24 & $m g C T / g R$ \\
\hline \multirow[t]{7}{*}{ UAE } & Yield & & 45.0 & 500.0 & 71.4 & 73.30 & \pm 4.51 & $\%$ \\
\hline & $Y_{1}$ & $C 1$ & 45.0 & 500.0 & 40.9 & 17.90 & \pm 2.44 & $m g C 1 / g P d w$ \\
\hline & & $C 2$ & 36.0 & 360.0 & 47.9 & 7.64 & \pm 1.13 & $m g C 2 / g P d w$ \\
\hline & & $C T$ & 45.0 & 432.3 & 42.8 & 23.83 & \pm 2.44 & $m g C T / g P d w$ \\
\hline & $Y_{2}$ & $C 1$ & 45.0 & 426.9 & 26.1 & 32.39 & \pm 3.29 & $m g C 1 / g R$ \\
\hline & & $C 2$ & 22.7 & 300.0 & 41.7 & 20.55 & \pm 3.21 & $m g C 2 / g R$ \\
\hline & & $C T$ & 26.1 & 296.6 & 39.1 & 51.76 & \pm 3.70 & $m g C T / g R$ \\
\hline \multicolumn{9}{|c|}{ (B) Global optimal extraction conditions } \\
\hline \multirow[t]{7}{*}{ HAE } & Yield & & 30.0 & 30.0 & 0.0 & 44.85 & \pm 8.12 & $\%$ \\
\hline & $Y_{1}$ & $C 1$ & & & & 8.55 & \pm 1.73 & $m g C 1 / g P d w$ \\
\hline & & $C 2$ & & & & 2.26 & \pm 0.29 & $m g C 2 / g P d w$ \\
\hline & & $C T$ & & & & 10.60 & \pm 1.11 & $m g C T / g P d w$ \\
\hline & $Y_{2}$ & $C 1$ & & & & 16.79 & \pm 2.18 & $m g C 1 / g R$ \\
\hline & & $C 2$ & & & & 4.47 & \pm 0.86 & $m g C 2 / g R$ \\
\hline & & $C T$ & & & & 20.83 & \pm 2.76 & $m g C T / g R$ \\
\hline \multirow[t]{7}{*}{ UAE } & Yield & & 42.9 & 386.3 & 46.1 & 61.21 & \pm 6.21 & $\%$ \\
\hline & $Y_{1}$ & $C 1$ & & & & 16.17 & \pm 1.22 & $m g C 1 / g P d w$ \\
\hline & & $C 2$ & & & & 7.38 & \pm 1.91 & $m g C 2 / g P d w$ \\
\hline & & $C T$ & & & & 23.08 & \pm 2.96 & $m g C T / g P d w$ \\
\hline & $Y_{2}$ & $C 1$ & & & & 29.72 & \pm 3.19 & $m g C 1 / g R$ \\
\hline & & $C 2$ & & & & 12.76 & \pm 1.91 & $m g C 2 / g R$ \\
\hline & & $C T$ & & & & 47.57 & \pm 4.37 & $m g C T / g R$ \\
\hline
\end{tabular}

higher amounts were obtained when water $(S=0 \%)$ was used as the extraction solvent. In turn, the effects of $t$ and $T$ were less marked, with the lowest tested ranges leading to the highest total anthocyanin values. For this method, the extraction conditions originating the higher response values were similar, regardless of the considered response format, except for the variable $T$. Table 3 shows that it was possible to obtain $8.57 \pm 2.07 \mathrm{mg} / \mathrm{g} \mathrm{P}$ and $2.66 \pm 1.15 \mathrm{mg} / \mathrm{g} \mathrm{P}$ of $C 1$ and $C 2$ from $H$. sabdariffa calyces, respectively, when applying the following HAE conditions: $t=45.0 \mathrm{~min}, S=0.0 \%$ ethanol, $\mathrm{v} / \mathrm{v}$, and $T=30$ or $90^{\circ} \mathrm{C}$ for $C 1$ and $C 2$, respectively. The residue or extract obtained under the same extraction conditions contained approximately the double amount of $C 1(16.81 \pm 2.37 \mathrm{mg} / \mathrm{g} \mathrm{R})$ and $C 2(4.59 \pm 1.24 \mathrm{mg} / \mathrm{g} \mathrm{R})$.

The extraction of anthocyanins followed a different trend when using UAE. Fig. 1 shows that all variables caused accented response surface curvatures, as also indicated by the corresponding parametric values (Table A2). Moreover, contrary to the one verified for HAE, the extraction conditions differed according to the considered response format. However, in both cases, there was a strong $t \times P$ interaction with a positive impact on the obtained total anthocyanin contents, especially for $Y_{2}$. Interactions between $t$ and $S$ were also noted. Applying this method, it was possible to recover $17.90 \pm 2.44 \mathrm{mg} / \mathrm{g} \mathrm{P}$ and $7.64 \pm 1.13 \mathrm{mg} / \mathrm{g} P$ of $C 1$ and $C 2$, respectively, from the dried red flower calyces (Table 3). In turn, $1 \mathrm{~g}$ of residue contained $32.39 \pm 3.29 \mathrm{mg}$ of $C 1$ and $20.55 \pm 3.21 \mathrm{mg}$ of $C 2$ when using the following conditions: $t=45.0 \mathrm{~min}, \quad P=426.9 \mathrm{~W}$ and $S=26.1 \%$ ethanol, v/v, and $t=22.7 \mathrm{~min}, P=300.0 \mathrm{~W}$ and $S=41.7 \%$ ethanol, v/ $\mathrm{v}$, respectively. All these values were much higher than those obtained by HAE (approximately twice). Moreover, the effectiveness of the applied UAE process was highlighted since the obtained anthocyanin levels are much higher than those reported in other studies (Table 1).

The $H$. sabdariffa calyces are a promising source of anthocyanins for potential use as natural red colorants, since the amounts achieved by applying the optimal extraction conditions are superior to those already found in the fruits of Prunus avium L. (sweet cherry, $2.49 \mathrm{mg} / \mathrm{g} \mathrm{P} \mathrm{fw}$ ) (Blackhall, Berry, Davies, \& Walls, 2018) and Aristotelia chilensis L. (maqui, $9.84 \mathrm{mg} / \mathrm{g} \mathrm{P} \mathrm{dw}$ ) (Gironés-Vilaplana et al., 2014), tubers of Ipomoea batatas $\mathrm{L}$. (purple sweet potato, $2.29 \mathrm{mg} / \mathrm{g} \mathrm{P} \mathrm{dw}$ ) (Cai et al., 2016), and purple pods of Vigna unguiculata ssp. sesquipedalis L. (yardlong bean, $8.81 \mathrm{mg} / \mathrm{g} \mathrm{P} \mathrm{dw}$ ) (Tae et al., 2010). The anthocyanin-based colorants can replace the artificial counterparts and provide healthpromoting effects (Castañeda-Ovando, de Pacheco-Hernández, \& PáezHernández, Rodríguez, \& Galán-Vidal, 2009; Martins et al., 2016).

\subsubsection{Efficiency of HAE vs. UAE}

As discussed above, the extraction of anthocyanins from the red flower calyces of $H$. sabdariffa was differently affected by the tested HAE and UAE methods. The highest yields were obtained using the nonconventional UAE method, which promotes the rupture of the plant tissue through cavitation forces and enhances the solvent entrance into the cells with consequent release of the intracellular compounds into the solvent, thus intensifying mass transfer phenomena (Antonio et al., 2016; Misra et al., 2017). This method yielded $51.76 \pm 3.70 \mathrm{mg} \mathrm{CT/ \textrm {g }}$ R when applying: $t=26.1 \mathrm{~min}, P=296.6 \mathrm{~W}$, and $S=39.1 \%$ ethanol, $\mathrm{v} / \mathrm{v}$, whereas HAE originated $20.86 \pm 1.24 \mathrm{mg} C T / \mathrm{g} \mathrm{R}$ when: $t=30.0 \mathrm{~min}, T=30.0^{\circ} \mathrm{C}$, and $S=0.0 \%$ ethanol, $\mathrm{v} / \mathrm{v}$. These optimized methods shared some similarities in terms of $T\left(\sim 30^{\circ} \mathrm{C}\right)$ and $t$ (26-30 min), thus indicating that the lower HAE values were not caused by thermal degradation of these compounds. In contrast, the response 


\section{A: Optimized RSM variables}

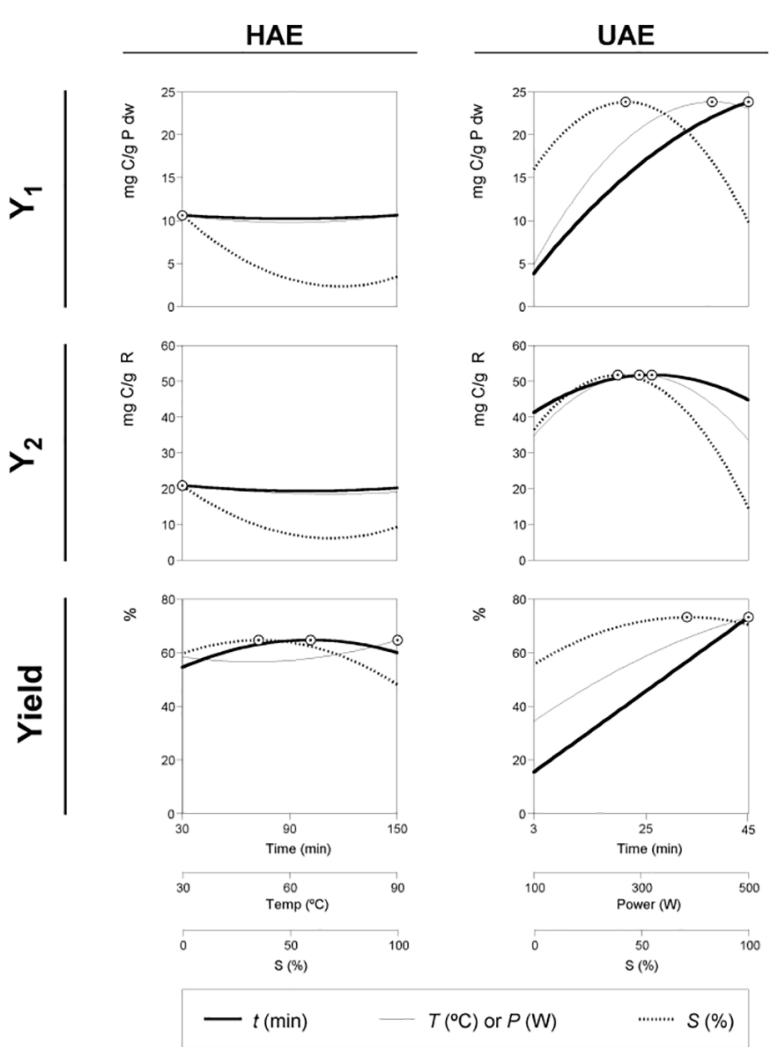

\section{B: Solid-to-liquid ratio patterns}
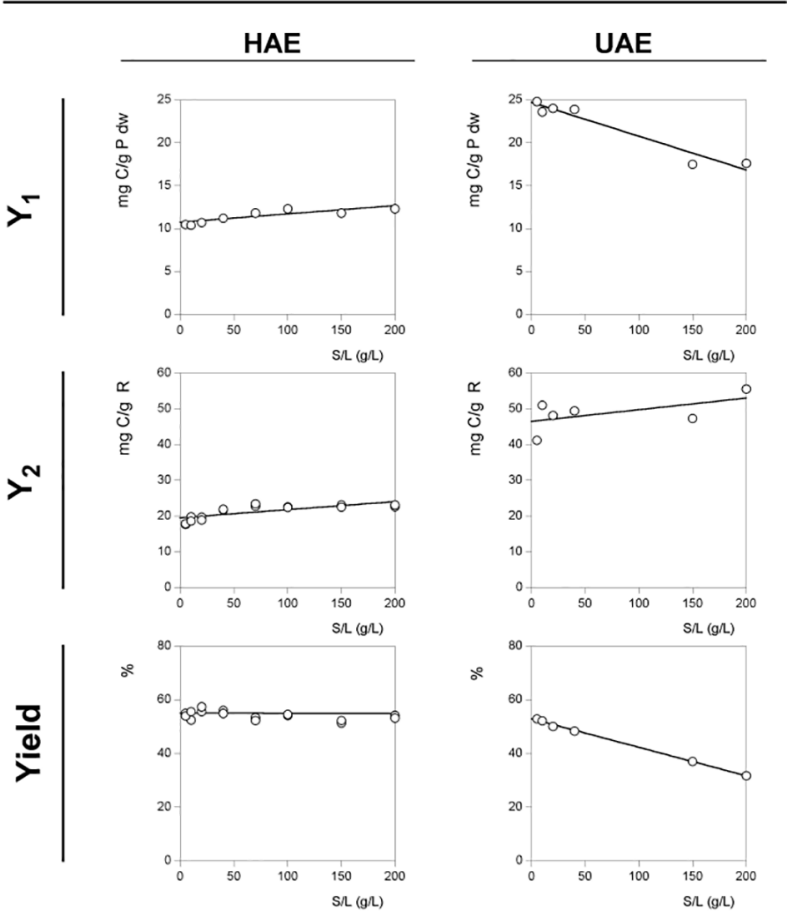

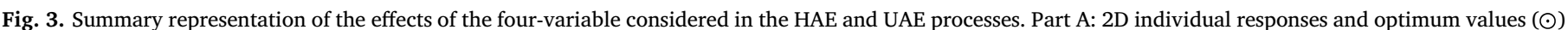

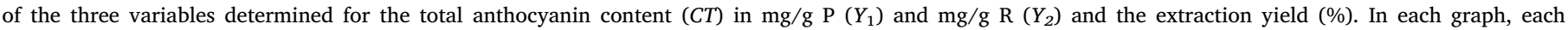

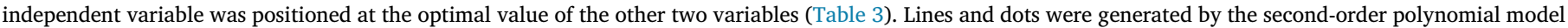

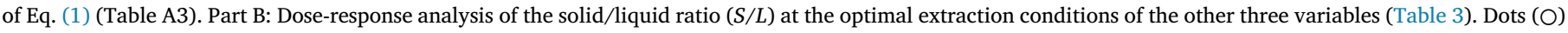
represent the experimental values and lines show the pattern predicted by linear equation (parametric values in Table A4).

optimum of UAE was achieved with the application of ultrasound and a higher ethanol proportion (meaning higher energy and solvent costs), while water was a suitable solvent for HAE. Nevertheless, the different maximum values achievable by each method are quite different and must be considered when selecting the most appropriate one.

In order to determine the most cost-effective option, it would be interesting to perform a life-cycle cost analysis (LCCA), not only of the sole extraction process as an individual unit operation, but considering the entire supply chain, including the production and harvesting of the plant material, equipment investment, natural resources and energy consumption, and environment hazardous emissions. A comparative LCCA between conventional solvent extraction and innovative methods using microwaves and ultrasounds was performed by Kyriakopoulou, Papadaki, and Krokida (2015), which found UAE the most viable and environmental friendly method to recover $\beta$-carotene from microalgae. In our study, the effects of the $S / L$ variable were investigated to obtain more information about the efficiency of each extraction method.

\subsubsection{Optimal extraction conditions for maximizing the responses criteria}

Although the effects described above provided a guiding range of conditions maximizing the defined responses, optimal values can be determined using a simple method tool to solve nonlinear problems. The results of the application of this simple procedure are presented in Table 3 (part A), in which the extraction conditions that maximize each response in individual and global terms are provided. Additionally, Fig. 3 (part A) summarizes the information derived from the mathematical equations, where 2D graphs are presented as a function of all assessed variables. These variables were positioned at the optimal global values of the other two variables (Table 3) (part B). For the three variables optimized for the recovery of total anthocyanins $(C T)$ in $\mathrm{mg} / \mathrm{g}$ $\mathrm{P}\left(Y_{1}\right)$ and $\mathrm{mg} / \mathrm{g} \mathrm{R}\left(Y_{2}\right)$ and extraction yield (\%), the predicted individual responses are represented by lines and optimum values by points $(\odot)$. The determined global optimal extraction conditions were experimentally tested to confirm the accuracy of the presented results and to assess the dose-response effect of the $S / L$ variable.

\subsection{Dose-response analysis of the solid/liquid ratio at the optimum conditions}

Reduced extraction time and low solvent consumption are some of the desired requirements when designing novel extraction methods. The solvent volume should be sufficient only to dissolve the target compounds and promote mass transfer (Pinela et al., 2016). At industrial scale, higher solid/liquid ratios $(S / L)$ are desirable to maximize the extraction yield with minimal solvent consumption, thus making the process more productive and sustainable. The extraction rate is also affected by the mass transfer resistance associated with the matrix structure (Marco, Agnese, \& Giuseppe, 2012). The studies on $S / L$ were performed at the global optimal conditions predicted by the polynomial models obtained for each extraction technique as previously described. Preliminary results indicated that the experimental limit value was proximal to $200 \mathrm{~g} / \mathrm{L}$. Therefore, the experiment was designed to assess 
the dose-response effects of the $S / L$ variable between $5 \mathrm{~g} / \mathrm{L}$ and $200 \mathrm{~g} / \mathrm{L}$.

Fig. 3 (part B) shows the dose-responses analysis of $S / L$ at the optimal global extraction conditions of the other three variables (Table 3 part B), where it is also possible to observe that the responses achieved by HAE and UAE are consistent with those previously obtained. In these 2D representations, dots $(O)$ represent the experimental values and lines show the pattern predicted by a simple linear relation with intercept (parametric values in Table A4). Based on the parametric values presented in Table A4, a consistency was found between the $C T$ values (for both $Y_{1}$ and $Y_{2}$ response formats) and those previously obtained for HAE and UAE (Table 3). Consequently, the dose response is explained by the slope $(m)$ of the linear relation. Negative values of $m$ describe decreasing extraction patterns as the $S / L$ increases, and positive values describe increasing extraction patterns as the $S / L$ increases, while a constant pattern is shown when the $m$ value is $n s$ (or zero). As can be observed, two cases showed negative $m$ values (the extraction efficiency increases as the $S / L$ rate decreases), and one case showed non-significant values, or a zero value of $m$ (the efficiency doesn't change as the $S / L$ increases). In all the other cases the $m$ showed positive values (the efficiency increases as the $S / L$ increases). The reliability of the obtained linear fittings is strongly consistent. In fact, high coefficients of determination were obtained $\left(R^{2} \geq 0.94\right)$ indicating a good agreement between predicted patterns and the obtained experimental data, validating the mathematical analysis selected to describe the reached solutions. The conclusions derived from this analysis are described below:

- For the $Y_{1}$ value format, the parametric values for HAE were $b=10.76 \pm 1.31 \mathrm{mg} \mathrm{CT} / \mathrm{g} \mathrm{P} \mathrm{dw}$ and $m=0.0097 \pm 0.001$, with $R^{2}=0.9510$; while for UAE, $b=24.47 \pm 2.37 \mathrm{mg} \mathrm{CT} / \mathrm{g} \mathrm{P} \mathrm{dw}$ and $m=-0.0393 \pm 0.019$, with $R^{2}=0.9765$. For the HAE process, as the $S / L$ increases, the extraction also slightly increases, leading to an increment of $\sim 15 \%$ in the extracted compounds, when changing from $5 \mathrm{~g} / \mathrm{L}$ (lower tested value) to $200 \mathrm{~g} / \mathrm{L}$ (maximum tested experimental value). On the other hand, the observed decrease for UAE is relatively strong, which means that the increase of $1 \mathrm{~g} / \mathrm{L}$ implies the loss of $0.0393 \pm 0.019 \mathrm{mg} C T / \mathrm{g} \mathrm{P} \mathrm{dw}$. Such values produce losses of $\sim 25 \%$ when applying $200 \mathrm{~g} / \mathrm{L}$, comparatively with the tested lower value. Therefore, when working at the most economically attractive $S / L$ value $(200 \mathrm{~g} / \mathrm{L})$, both solutions will reach similar results.

- For the $Y_{2}$ value format, the parametric values for HAE were $b=19.53 \pm 1.38 \mathrm{mg} \mathrm{CT} / \mathrm{g} \mathrm{R}$ and $m=0.0225 \pm 0.0091$, with $R^{2}=0.9434$; while for UAE, $b=46.26 \pm 2.74 \mathrm{mg} \mathrm{CT} / \mathrm{g} \mathrm{R}$ and $m=0.0325 \pm 0.0098$, with $R^{2}=0.9674$. The positive $m$ values show that the $S / L$ increase leads to an increase in the extraction ability, conducting to a maximum extraction value when using $200 \mathrm{~g} / \mathrm{L}$. Nevertheless, the quantity extracted by UAE is nearly 3fold superior to the quantity obtained by HAE.

- For the Yield value format, the parametric values for HAE were $b=55.14 \pm 3.56 \%$ and a $n s$ value of $m$ (i.e., the obtained amount of residue does not vary as a function of the $S / L$ increase), with $R^{2}=0.9794 ; \quad$ whereas for UAE, $b=52.20 \pm 2.98 \%$ and $m=-0.106 \pm 0.007$, with $R^{2}=0.9975$.

These results are in accordance with the ones reported in the literature, where UAE has been identified as a technique with potential to improve the extraction yield through the intensification of the mass transfer between the plant material and the solvent (Tomšik et al., 2016). Probably, the implosion of the cavitation bubbles generated during sonication led to an improved cell disruption and particle breakdown, which facilitated the release of the extractable compounds and allowed a greater penetration of the solvent into the sample matrix, thus increasing the contact surface area between the solid and liquid phases (Chemat et al., 2017b; Tomšik et al., 2016). However, in order to propose a more accurate sonication mechanism and to visualize the effects, it would be interesting to investigate different mechanisms involved during UAE, such as fragmentation, erosion, capillarity, detexturation and sonoporation, as well as the influencing parameters (Chemat et al., 2017b). Therefore, macroscopic and cyto-histochemical analyses, scanning electron microscopy (SEM), and environmental scanning electron microscopy (e-SEM), among other observations, should be performed (Khadhraoui et al., 2018).

The concept of "green extraction" is aligned with the societal challenges of the 21st century, to protect both the consumers and environment. This approach also promotes competition in the industrial sector, making it more innovative, efficient and sustainable (Chemat et al., 2017a; Khadhraoui et al., 2018; Sicaire et al., 2016). Therefore, the UAE process herein optimized can be adopted by industrials interested in replacing their traditional extraction process with this more ecological and competitive method. For this, experiments should be conducted from the laboratory to pilot-scale, to lead to the implementation of UAE at the industrial-scale (using countercurrent extractors) (Chemat et al., 2017a; Sicaire et al., 2016), which will be of great importance to recover pigments, aromas and antioxidants from plant materials (in this case, anthocyanins from $H$. sabdariffa calyces). However, UAE finds other relevant applications in the food, nutraceutical, pharmaceutical and bioenergy industries (Chemat et al., 2017a, 2017b; Meullemiestre et al., 2016; Sicaire et al., 2016).

\section{Conclusions}

Nowadays, consumers are increasingly choosing food products formulated with natural additives due to the understanding of the strong relation between health and diet. Therefore, it is important for the industrial food sector to find novel sources and efficient extraction methods to support the production of bio-based ingredients, including colorants. In this study, two extraction methods were applied, and optimized by combining the effects of three relevant independent variables, to maximize the recovery of anthocyanins from the red calyces of $H$. sabdariffa. The achieved experimental data were successfully fitted to the theoretical models used to determine the optimal extraction conditions. UAE was the most efficient method; it allowed to recover $23.83 \pm 2.44 \mathrm{mg}$ of the target anthocyanins per $1 \mathrm{~g}$ of dried plant material and obtain $51.76 \mathrm{mg}$ of these pigments in $1 \mathrm{~g}$ of residue (or extract). For the $S / L$ variable, whose effects were assessed at the optimum conditions, firstly determined for the defined three variables, the positive $m$ values obtained for $Y_{2}$ showed that the $S / L$ increase leads to an increase in the extraction ability, conducting to maximum values at $200 \mathrm{~g} / \mathrm{L}$. Furthermore, the amount of anthocyanins obtained by UAE was nearly 3-fold higher than the amount obtained by HAE. According to these results, it can be stated that $H$. sabdariffa calyces can be used as a viable source of anthocyanins to produce bio-based colouring agents, being one of the richest anthocyanin containing sources reported in the literature. In addition, this bench-scale application study can support the scale-up of natural colorants production, which is of interest to industrial suppliers of the food, pharmaceutical and cosmetic sectors, among others.

\section{Acknowledgements}

The authors are grateful to the Foundation for Science and Technology (FCT, Portugal) and FEDER under Programme PT2020 for financial support to CIMO (UID/AGR/00690/2013), FEDER through POCI-COMPETE2020 and FCT for financial support to LA LSRE-LCM (POCI-01-0145-FEDER-006984), J. Pinela (UID/AGR/00690/ 2013_DNAABN) and L. Barros contract. This work is funded by the European Regional Development Fund (ERDF) through the Regional Operational Program North 2020, within the scope of Project NORTE01-0145-FEDER-023289: DeCodE and project Mobilizador Norte-010247-FEDER-024479: ValorNatural ${ }^{\circledR}$. The authors are also grateful to FEDER-Interreg España-Portugal programme for financial support through the project 0377_Iberphenol_6_E. To the Xunta de Galicia for 


\section{(1) interreg}

\section{Appendix A. Supplementary material}

Supplementary data to this article can be found online at https:// doi.org/10.1016/j.foodchem.2018.09.118.

\section{References}

Alarcón-Alonso, J., Zamilpa, A., Aguilar, F. A., Herrera-Ruiz, M., Tortoriello, J., \& Jimenez-Ferrer, E. (2012). Pharmacological characterization of the diuretic effect of Hibiscus sabdariffa Linn (Malvaceae) extract. Journal of Ethnopharmacology, 139(3), 751-756.

Ali, B. H., Al Wabel, N., \& Blunden, G. (2005). Phytochemical, pharmacological and toxicological aspects of Hibiscus sabdariffa L.: A review. Phytotherapy Research, 19(5), 369-375.

Almeida, H. H. S., Barros, L., Barreira, J. C. M., Calhelha, R. C., Heleno, S. A., Sayer, C., ... Ferreira, I. C. F. R. (2018). Bioactive evaluation and application of different formulations of the natural colorant curcumin (E100) in a hydrophilic matrix (yogurt). Food Chemistry, 261, 224-232.

Antonio, A. L., Pereira, E., Pinela, J., Heleno, S., Pereira, C., \& Ferreira, I. C. F. R. (2016). Determination of antioxidant compounds in foodstuff. Food safety: Innovative analytical tools for safety assessment (pp. 179-220). Hoboken, NJ, USA: John Wiley \& Sons Inc.

Beye, C., Hiligsmann, S., Tounkara, L. S., \& Thonart, P. (2017). Anthocyanin content of two Hibiscus sabdariffa cultivars grown in Senegal. Agronomie Africaine, 29(1), 63-68.

Blackhall, M. L., Berry, R., Davies, N. W., \& Walls, J. T. (2018). Optimized extraction of anthocyanins from Reid Fruits' Prunus avium 'Lapins' cherries. Food Chemistry, 256, 280-285.

Cai, Z., Qu, Z., Lan, Y., Zhao, S., Ma, X., Wan, Q., ... Li, P. (2016). Conventional, ultrasound-assisted, and accelerated-solvent extractions of anthocyanins from purple sweet potatoes. Food Chemistry, 197, 266-272.

Carle, R., \& Schweiggert, R. M. (2016). Handbook on natural pigments in food and beverages: Industrial applications for improving food color (1st ed.). Woodhead Publishing.

Carocho, M., Barros, L., Barreira, J. C. M., Calhelha, R. C., Soković, M., Fernández-Ruiz, V., ... Ferreira, I. C. F. R. (2016). Basil as functional and preserving ingredient in "Serra da Estrela" cheese. Food Chemistry, 207, 51-59.

Carocho, M., Morales, P., \& Ferreira, I. C. F. R. (2015). Natural food additives: Quo vadis? Trends in Food Science \& Technology, 45(2), 284-295.

Castañeda-Ovando, A., Pacheco-Hernández, M.de L., Páez-Hernández, M. E., Rodríguez, J. A., \& Galán-Vidal, C. A. (2009). Chemical studies of anthocyanins: A review. Food Chemistry, 113(4), 859-871.

Chemat, F., Rombaut, N., Meullemiestre, A., Turk, M., Perino, S., Fabiano-Tixier, A.-S., \& Abert-Vian, M. (2017a). Review of green food processing techniques. Preservation, transformation, and extraction. Innovative Food Science \& Emerging Technologies, 41, 357-377.

Chemat, F., Rombaut, N., Sicaire, A. G., Meullemiestre, A., Fabiano-Tixier, A. S., \& AbertVian, M. (2017b). Ultrasound assisted extraction of food and natural products. Mechanisms, techniques, combinations, protocols and applications. A review. Ultrasonics Sonochemistry, 34, 540-560.

Comuzzi, C., Polese, P., Melchior, A., Portanova, R., \& Tolazzi, M. (2003). SOLVERSTAT: A new utility for multipurpose analysis. An application to the investigation of dioxygenated Co(II) complex formation in dimethylsulfoxide solution. Talanta, 59(1), 67-80.

Corrales, M., Toepfl, S., Butz, P., Knorr, D., \& Tauscher, B. (2008). Extraction of anthocyanins from grape by-products assisted by ultrasonics, high hydrostatic pressure or pulsed electric fields: A comparison. Innovative Food Science and Emerging Technologies, 9(1), 85-91.

Da-Costa-Rocha, I., Bonnlaender, B., Sievers, H., Pischel, I., \& Heinrich, M. (2014). Hibiscus sabdariffa L. - A phytochemical and pharmacological review. Food Chemistry, 165, 424-443.

de Levie, R. (2012). Advanced excel for scientific data analysis (3rd ed.). Atlantic Academic LLC.

Du, Q., Jerz, G., \& Winterhalter, P. (2004). Isolation of two anthocyanin sambubiosides from bilberry (Vaccinium myrtillus) by high-speed counter-current chromatography. Journal of Chromatography A, 1045(1-2), 59-63.

Garcia-Mendoza, M.del P., Espinosa-Pardo, F. A., Baseggio, A. M., Barbero, G. F., Maróstica Junior, M. R., Rostagno, M. A., \& Martínez, J. (2017). Extraction of phenolic compounds and anthocyanins from juçara (Euterpe edulis Mart.) residues using pressurized liquids and supercritical fluids. The Journal of Supercritical Fluids, 119, 9-16.
Gironés-Vilaplana, A., Baenas, N., Villaño, D., Speisky, H., García-Viguera, C., \& Moreno, D. A. (2014). Evaluation of Latin-American fruits rich in phytochemicals with biological effects. Journal of Functional Foods, 7(1), 599-608.

Heleno, S. A., Diz, P., Prieto, M. A., Barros, L., Rodrigues, A., Barreiro, M. F., \& Ferreira, I. C. F. R. (2016). Optimization of ultrasound-assisted extraction to obtain mycosterols from Agaricus bisporus L. by response surface methodology and comparison with conventional Soxhlet extraction. Food Chemistry, 197, 1054-1063.

Ifie, I., Ifie, B. E., Ibitoye, D. O., Marshall, L. J., \& Williamson, G. (2018). Seasonal variation in Hibiscus sabdariffa (Roselle) calyx phytochemical profile, soluble solids and $\alpha$-glucosidase inhibition. Food Chemistry, 261, 164-168.

Jabeur, I., Pereira, E., Barros, L., Calhelha, R. C., Soković, M., Oliveira, M. B. P. P. \& Ferreira, I. C. F. R. (2017). Hibiscus sabdariffa L. as a source of nutrients, bioactive compounds and colouring agents. Food Research International, 100, 717-723.

Kemmer, G., \& Keller, S. (2010). Nonlinear least-squares data fitting in excel spreadsheets. Nature Protocols, 5(2), 267-281.

Khadhraoui, B., Turk, M., Fabiano-Tixier, A. S., Petitcolas, E., Robinet, P., Imbert, R., .. Chemat, F. (2018). Histo-cytochemistry and scanning electron microscopy for studying spatial and temporal extraction of metabolites induced by ultrasound. Towards chain detexturation mechanism. Ultrasonics Sonochemistry, 42, 482-492.

Kyriakopoulou, K., Papadaki, S., \& Krokida, M. (2015). Life cycle analysis of $\beta$-carotene extraction techniques. Journal of Food Engineering, 167, 51-58.

Liazid, A., Guerrero, R. F., Cantos, E., Palma, M., \& Barroso, C. G. (2011). Microwave assisted extraction of anthocyanins from grape skins. Food Chemistry, 124(3), 1238-1243.

López, C. J., Caleja, C., Prieto, M. A., Barreiro, M. F., Barros, L., \& Ferreira, I. C. F. R. (2018). Optimization and comparison of heat and ultrasound assisted extraction techniques to obtain anthocyanin compounds from Arbutus unedo L. fruits. Food Chemistry, 264, 81-91.

Marco, B., Agnese, C., \& Giuseppe, T. (2012). Quality preservation and cost effectiveness in the extraction of nutraceutically - Relevant fractions from microbial and vegetal matrices. In B. Valdez (Ed.). Scientific, health and social aspects of the food industry (pp. 488). InTech.

Marić, M., Grassino, A. N., Zhu, Z., Barba, F. J., Brnčić, M., \& Rimac Brnčić, S. (2018). An overview of the traditional and innovative approaches for pectin extraction from plant food wastes and by-products: Ultrasound-, microwaves-, and enzyme-assisted extraction. Trends Food Science \& Technology, 76, 28-37.

Martins, N., Roriz, C. L., Morales, P., Barros, L., \& Ferreira, I. C. F. R. (2016). Food colorants: Challenges, opportunities and current desires of agro-industries to ensure consumer expectations and regulatory practices. Trends in Food Science \& Technology, $52,1-15$.

Meullemiestre, A., Breil, C., Abert-Vian, M., \& Chemat, F. (2016). Microwave, ultrasound, thermal treatments, and bead milling as intensification techniques for extraction of lipids from oleaginous Yarrowia lipolytica yeast for a biojetfuel application. Bioresource Technology, 211, 190-199.

Misra, N. N., Martynenko, A., Chemat, F., Paniwnyk, L., Barba, F. J., \& Jambrak, A. R (2017). Thermodynamics, transport phenomena, and electrochemistry of external field-assisted nonthermal food technologies. Critical Reviews in Food Science and Nutrition, 1-32.

Pinela, J., Prieto, M. A., Barreiro, M. F., Carvalho, A. M., Oliveira, M. B. P. P., Curran, T. P., \& Ferreira, I. C. F. R. (2017). Valorisation of tomato wastes for development of nutrient-rich antioxidant ingredients: A sustainable approach towards the needs of the today's society. Innovative Food Science \& Emerging Technologies, 41, 160-171.

Pinela, J., Prieto, M. A., Barreiro, M. F., Carvalho, A. M., Oliveira, M. B. P. P., Vázquez, J. A., \& Ferreira, I. C. F. R. (2016). Optimization of microwave-assisted extraction of hydrophilic and lipophilic antioxidants from a surplus tomato crop by response surface methodology. Food and Bioproducts Processing, 98, 283-298.

Ramesh, M., \& Muthuraman, A. (2018). Flavoring and coloring agents: Health risks and potential problems. In A. M. Grumezescu, \& A. M. Holban (Eds.). Natural and artificial flavoring agents and food dyes (pp. 1-28). Academic Press.

Ranic, M., Nikolic, M., Pavlovic, M., Buntic, A., Siler-Marinkovic, S., \& DimitrijevicBrankovic, S. (2014). Optimization of microwave-assisted extraction of natural antioxidants from spent espresso coffee grounds by response surface methodology Journal of Cleaner Production, 80, 69-79.

Salazar-González, C., Vergara-Balderas, F. T., Ortega-Regules, A. E., \& Guerrero-Beltrán, J.Á. (2012). Antioxidant properties and color of Hibiscus sabdariffa extracts. Ciencia e Investigación Agraria, 39(1), 79-90.

Sharma, H. K., Sarkar, M., Choudhary, S. B., Kumar, A. A., Maruthi, R. T., Mitra, J., \& Karmakar, P. G. (2016). Diversity analysis based on agro-morphological traits and microsatellite based markers in global germplasm collections of roselle (Hibiscus sabdariffa L.). Industrial Crops and Products, 89, 303-315. 
Shi, P., \& Tsai, C.-L. (2002). Regression model selection - A residual likelihood approach. Journal of the Royal Statistical Society: Series B (Statistical Methodology), 64(2), $237-252$.

Sicaire, A.-G., Vian, M. A., Fine, F., Carré, P., Tostain, S., \& Chemat, F. (2016). Ultrasound induced green solvent extraction of oil from oleaginous seeds. Ultrasonics Sonochemistry, 31, 319-329.

Sindi, H. A., Marshall, L. J., \& Morgan, M. R. A. (2014). Comparative chemical and biochemical analysis of extracts of Hibiscus sabdariffa. Food Chemistry, 164, 23-29.

Tae, J. H., Lee, M. H., Park, C. H., Pae, S. B., Shim, K. B. O., Ko, J. M., .. Park, K. Y. (2010). Identification and characterization of anthocyanins in yard-long beans (Vigna unguiculata ssp. sesquipedalis L.) by high-performance liquid chromatography with diode array detection and electrospray ionization/mass spectrometry (HPLC-DADESI. Journal of Agricultural and Food Chemistry, 58(4), 2571-2576.
Tomšik, A., Pavlić, B., Vladić, J., Ramić, M., Brindza, J., \& Vidović, S. (2016) Optimization of ultrasound-assisted extraction of bioactive compounds from wild garlic (Allium ursinum L.). Ultrasonics Sonochemistry, 29, 502-511.

Vilkhu, K., Mawson, R., Simons, L., \& Bates, D. (2008). Applications and opportunities for ultrasound assisted extraction in the food industry - A review. Innovative Food Science and Emerging Technologies, 9(2), 161-169.

Yang, B., Zheng, J., Laaksonen, O., Tahvonen, R., \& Kallio, H. (2013). Effects of latitude and weather conditions on phenolic compounds in currant (Ribes spp.) cultivars. Journal of Agricultural and Food Chemistry, 61(14), 3517-3532.

Zhang, B., Mao, G., Zheng, D., Zhao, T., Zou, Y., Qu, H., ... Wu, X. (2014). Separation, identification, antioxidant, and anti-tumor activities of Hibiscus sabdariffa L. extracts. Separation Science and Technology, 49(9), 1379-1388. 